\title{
Role of chemiluminescence and radius of curvature in the stabilization of methane/helium lifted flames
}

Narayan P. Sapkal

Department of Mechanical Engineering, Pukyong National University, Nam-gu, Busan 608-739, South Korea

Corresponding Author Email: narayanpsapk@pukyong.ac.kr

https://doi.org/10.18280/ijht.360412

Received: 19 August 2017

Accepted: 24 October 2018

\section{Keywords:}

schmidt number, richardson number, buoyancy effect, chemiluminescence, edge flame speed

\begin{abstract}
The stabilization mechanism of non-premixed jet flames of methane diluted with helium has been investigated experimentally. Effects of fuel mole fraction, $X_{\mathrm{F}, \mathrm{O}}$ and nozzle diameter, $D$ on the lifted flame characteristics of diluted methane jets were studied. Such methane jet flames could be lifted despite the Schmidt number was less than unity. Regimes of lifted flames were evaluated according to Richardson number and liftoff height compared with the length of developing zone. Such flames obtained using $D=9.4 \mathrm{~mm}$ nozzle were stabilized due to buoyancy induced convection in buoyancy dominated regime whereas for $D=0.95$ $\mathrm{mm}$ nozzle methane jet flames could be lifted even at nozzle exit velocities much higher than stoichiometric laminar flame speed in jet momentum dominated regime. The chemiluminescence intensities of $\mathrm{OH}^{*}$ radical (good indicators of heat release rate) were measured using monochromatic system for these lifted flames. It was confirmed that, in jetmomentum dominated regime an increase in radius of curvature in addition to $\mathrm{OH}^{*}$ concentration stabilizes such lifted flames. Heat release rate near the triple point inferred by the $\mathrm{OH}^{*}$ chemiluminescence intensity was inversely proportional to $X_{\mathrm{F}, \mathrm{O}}$ and had maximum at blowout conditions.
\end{abstract}

\section{INTRODUCTION}

Laminar lifted non-premixed free and co-flow jet flames have been studied extensively to clarify the characteristics of flame stabilization, to develop laminar stretched flame-let model and to get the fundamental data for designing industrial burners [1-3]. It propagates along the stoichiometric contour due to the intrinsic nature of its leading edge that consists of lean and rich premixed flame wings and a trailing diffusion flame, all extending from a triple point. Thus, the stabilization mechanism is addressed to the balance between the tri-brachial flame speed and local axial flow velocity [1-2]. The propagation speed of tribrachial flame has also been investigated extensively [3-7] and it has been found that the mixture fraction gradient and flow redirection effect resulted from heat release rate are the two dominant factors that influences the propagation speed. The stability analysis [2] has been performed by assuming that the propagation speed is either constant or relatively insensitive to flow conditions [5]. The lifted flame is found to be stable (unstable) when the local flow velocity along the stoichiometric contour decreases (increases) with the axial distance in laminar free jets, which corresponds to the cases when Schmidt number, $S c$ of fuel is larger/smaller than unity [2]. Based on cold jet similarity solutions, experimentally it was shown that propane and n-butane fuels $(S c>1)$ exhibited stable lifted flames, while no stable lifted flames were observed for methane and ethane fuels $\left(S_{c}<1\right)$ in free jets [1]. Stationary lifted flames were also observed in highly diluted propane co-flow jet flames when relatively large size nozzle, O (10 mm), was used [8]. Lifted flame stabilization modes were identified in the developing and developed regions of such co-flow jets. It has been found that the buoyancy plays an important role of flame stabilization. Also stationary lifted flames for partially premixed or diluted methane were observed in the near field of co-flow jets [911] in buoyancy-dominated regime. However, in momentumdominated regime, they have not observed laminar lifted flames with a sub-millimeter size nozzle.

Concurrently, for the lifted flame in hot co-flow environment, the important chemical role of intermediate species [12] such as $\mathrm{OH}^{*}, \mathrm{CH}_{2} \mathrm{O}^{*}$ in flame stabilization (via reduction in ignition delay time) has been investigated. A recent series of experiments conducted on the methane flame has made available instantaneous, simultaneous, high resolution images of temperature, $\mathrm{OH}$ and $\mathrm{CH}_{2} \mathrm{O}$ mole fractions [13]. Investigating the behavior of the flame front, as defined by regions of peak heat release rate or reaction rate, has been of great interest to experimental combustion researchers. Though the product of $\mathrm{OH}$ and $\mathrm{CH}_{2} \mathrm{O}$ from LIF images or chemiluminescent signals [14] was used as a proxy for heat release rate in laminar premixed flames [15-16]. $\mathrm{OH}^{*}$ chemiluminescent intensity alone was also considered as the quantity proportional to heat release rate [17]. Correlation of edge flame speed to fuel concentration gradient in a propagating triple flame was addressed using the dependency of fuel concentration gradient upon the radius of curvature [3]. Additionally, the tri-brachial flame speed could be sensitively dependent upon many factors such as mixture strength, buoyancy, heat loss and Lewis number [18]. Furthermore, numerical studies have been done for lifted $\mathrm{H}_{2} / \mathrm{N}_{2}$ jet flame in a vitiated co-flow [19]. Also Convection phenomena was explained in previous studies [20]. 
This study is to further explore laminar lifted methane jet flames diluted with helium $\left(S_{c}<1\right)$. As an extension of the previous studies [9-11] that buoyancy effects could be the stabilization mechanism in laminar stationary lifted nitrogen diluted or partially premixed methane jet flames. The current study is to substantiate why such a laminar lifted flame can be stabilized even in jet momentum dominated regime. To check the effect of buoyancy, Richardson number, $R i$ was evaluated and chemiluminescence intensities of $\mathrm{OH}^{*}$ has been measured by monochromator. Also the radius of curvature, $r^{*}$ cur which is one of the main mechanism of the stabilization of tri-brachial flame is measured as well.

\section{EXPERIMENTAL SETUP}

Schematic diagram of experimental set-up is as shown in the Figure 1, which consists of a co-flow burner, flow controllers, visualization system and spectrum analysis system. Two different size nozzles of inner diameter $9.4 \mathrm{~mm}$ and $0.95 \mathrm{~mm}$ with $100 \mathrm{~cm}$ and $40 \mathrm{~cm}$ in length respectively, were used as central fuel nozzle in the co-flow burner. The co-flow air was supplied to the coaxial duct (with $90.4 \mathrm{~mm}$ i.d.) through glass beads and honeycomb for the velocity to be uniform. The tip of the fuel nozzle protruded $10.3 \mathrm{~mm}$ over the honeycomb. A quartz tube with $20 \mathrm{~cm}$ length and 90.4 $\mathrm{mm}$ inner diameter was placed on the honeycomb, to minimize outside disturbances. Pure grade of methane $(>99.95 \%)$ diluted with helium $(>99.99 \%)$ was supplied to the central nozzle.

High resolution monochromator (JOBIN YVON THR$1000, f=1000 \mathrm{~mm}, 1200$ groove $/ \mathrm{mm}$ ) and PMT (HamamatsuR920) was used to get the spectrum of chemiluminescent light. Two lens of focal length $100 \mathrm{~mm}$ were used to make one to one flame image. Light from flame base image on the $600 \mu \mathrm{m}$ optical fiber was fed to the monochromator. To increase signal intensity, entrance and exit slits of the monochromator were widely opened. Chemiluminescence intensities were obtained in the range of $300 \mathrm{~nm}$ to $600 \mathrm{~nm}$. The flow rates were controlled by mass flow controllers (ICDS Ltd.). The liftoff heights were measured by the cathetometer.

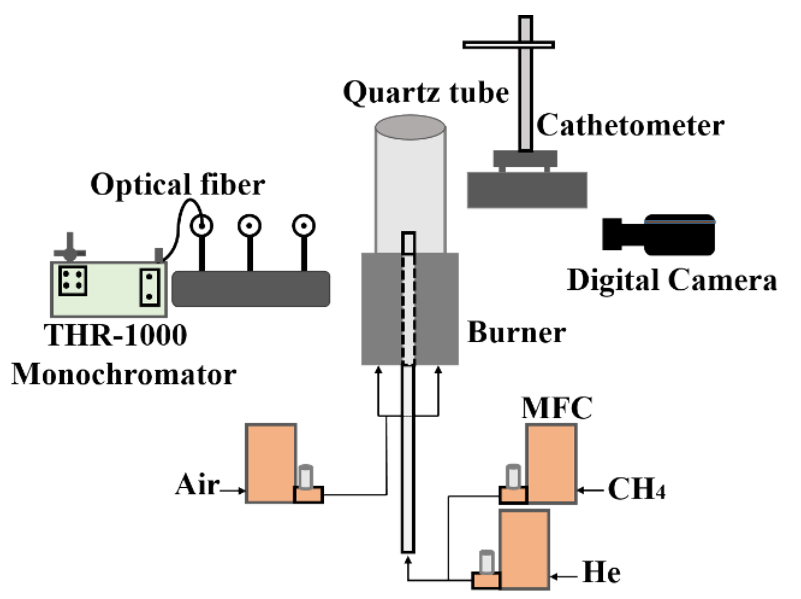

Figure 1. Schematic diagram of experimental set-up

\section{RESULTS AND DISCUSSIONS}

\subsection{Liftoff height}

The representative shape of methane jet flames diluted with helium for $D=9.4 \mathrm{~mm}$ with $V_{\mathrm{CO}}=10 \mathrm{~cm} / \mathrm{s}$, and $U_{\mathrm{O}}=8$ $\mathrm{cm} / \mathrm{s}$ was demonstrated in Figure 2(a). Despite the $S c$ number less than unity $\left(0.7<S_{c}<0.78\right)$ in the current experimental conditions, flame is lifted for $U_{\mathrm{O}}$ with $\mathrm{O}(10 \mathrm{~cm} / \mathrm{s})$. By decreasing $X_{\mathrm{F}, \mathrm{O}}$ at a fixed $U_{\mathrm{O}}$ the flame shape varies from a long lifted flame to a small triple flame just prior to flame blowout. Similar tendency can be obtained with $U_{\mathrm{O}}$ at a given $X_{\mathrm{F}, \mathrm{O}}$. Such lifted flame has the tri-brachial structure a rich premixed flame, a lean premixed one, and a trailing diffusion flame meet at a triple point as in laminar lifted propane flame [1]. Liftoff height as functions of $U_{\mathrm{O}}$ and $X_{\mathrm{F}, \mathrm{O}}$ was exhibited in Figure 2(b). The liftoff heights increase nonlinearly with $U_{\mathrm{O}}$ in the range of several millimeters to $181.7 \mathrm{~mm}$. Adding helium results in increase in the $H_{\mathrm{L}}$ at a given $U_{\mathrm{O}}$ until blowout occurs. Flame flickering occurs near the tip region [21] for $U_{\mathrm{O}}>10 \mathrm{~cm} / \mathrm{s}$. Even with flickering, its influence on the liftoff height was negligible.
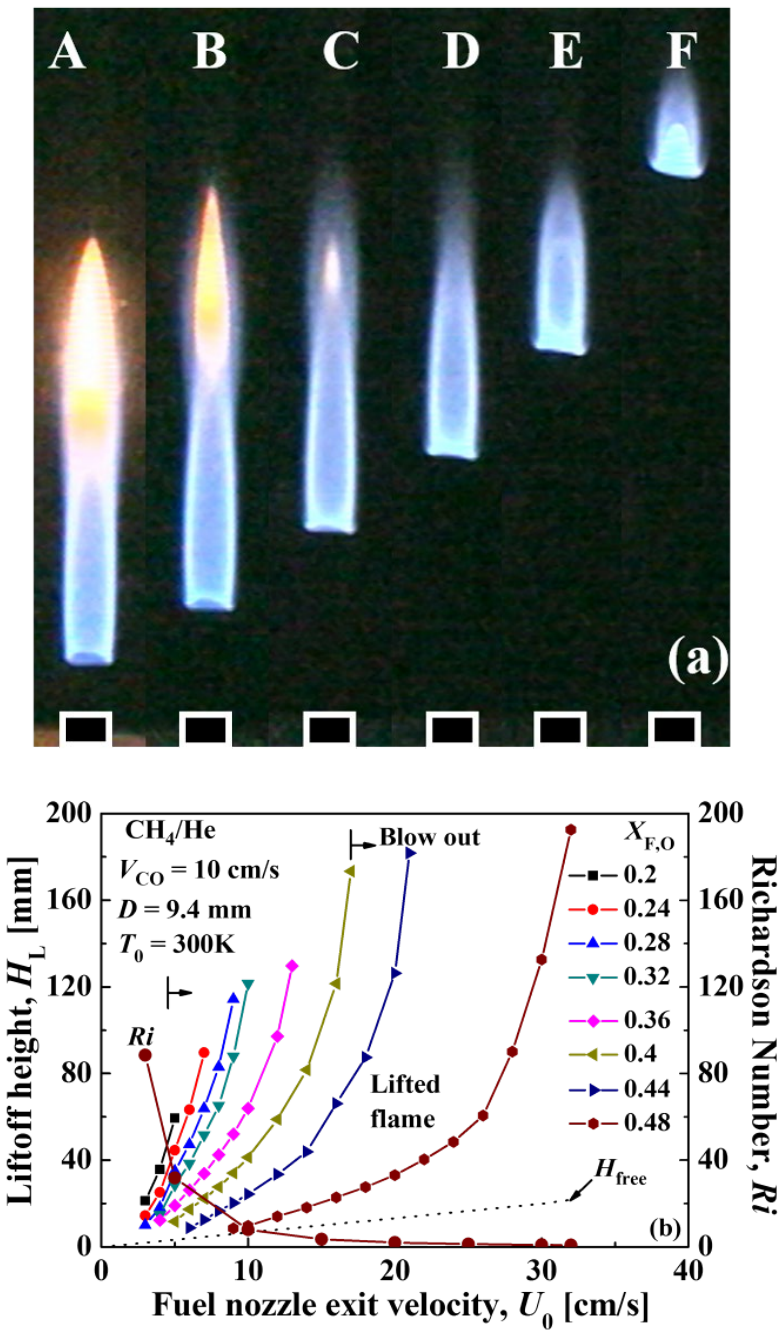

Figure 2. (a) Direct photographs of stationary lifted methane jet flames diluted with helium for $U_{\mathrm{O}}=8 \mathrm{~cm} / \mathrm{s}$, at (A) $X_{\mathrm{F}, \mathrm{O}}=$ 0.48 (B) 0.44 (C) 0.4 (D) 0.36 (E) 0.32 (F) 0.28 (b) Liftoff height variation of stationary lifted flames with fuel nozzle exit velocity for methane diluted with helium $(S c<1)$ at various fuel mole fractions 
For helium dilution cases with $D=0.95 \mathrm{~mm}$, lifted flame exists for $U_{\mathrm{O}}$ with $\mathrm{O}(100 \mathrm{~cm} / \mathrm{s})$, much higher than stoichiometric laminar flame speed as shown in Figure 3. Initially, experiments were conducted up to $300 \mathrm{~cm} / \mathrm{s}$. The direct photographs of the lifted flames for $U_{\mathrm{O}}=280 \mathrm{~cm} / \mathrm{s}$ at various $X_{\mathrm{F}, \mathrm{O}}$ was also demonstrated in Figure 3(a). The triple flame structure was attained at large $H_{\mathrm{L}}$. Addition of helium diluent and increase in the $U_{\mathrm{O}}$ causes a rise in the $H_{\mathrm{L}}$ nonlinearly until the flame is blown out as shown in the Figure 3(b). The $H_{\mathrm{L}}$ was in the range of 2.05 to $17.82 \mathrm{~mm}$.
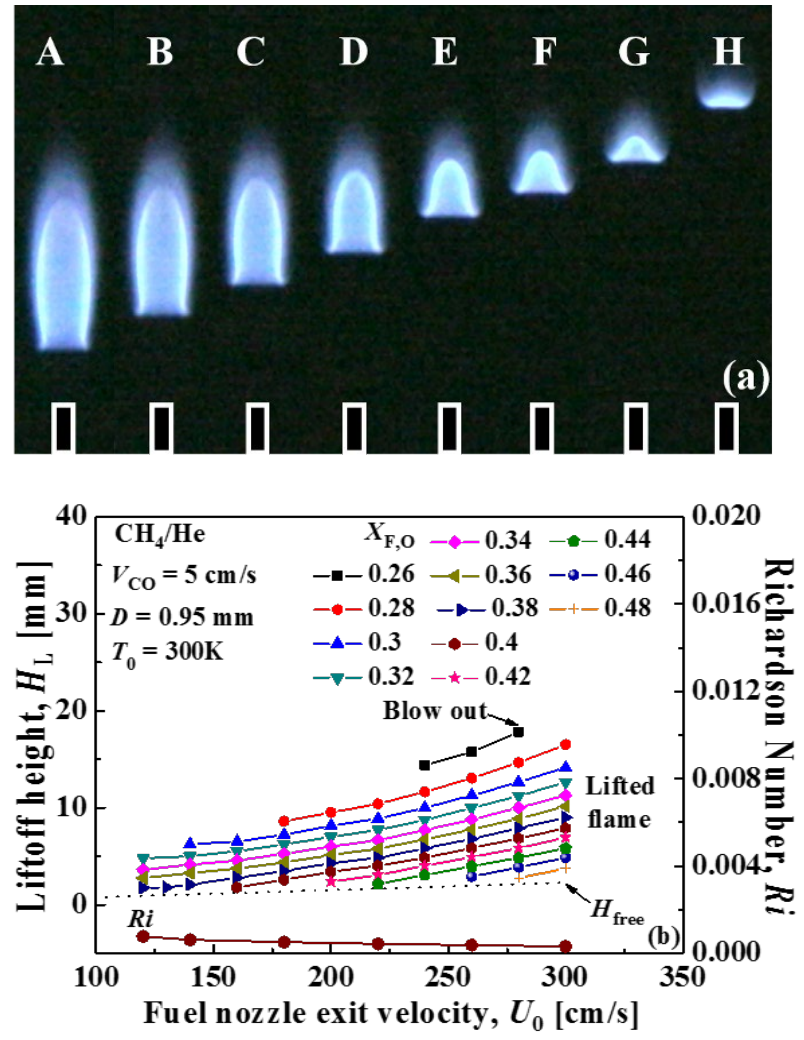

Figure 3. (a) Direct photographs of stationary lifted methane jet flames diluted with helium for $U_{\mathrm{O}}=280 \mathrm{~cm} / \mathrm{s}$, at (A) $X_{\mathrm{F}, \mathrm{O}}=$ 0.46 (B) 0.44 (C) 0.4 (D) 0.36 (E) 0.32 (F) 0.3 (G) 0.28 (H)

0.26 (b) Liftoff height variation of stationary lifted flames

with fuel nozzle exit velocity for methane diluted with helium $(S c<1)$ at various fuel mole fractions

Although, based on cold jet similarity solutions, experimentally it was shown that propane and n-butane fuels $(S c>1)$ exhibited stable lifted flames, while no stable lifted flames were observed for methane and ethane fuels $\left(S_{c}<1\right)$ in free jets [1]. But as shown in the Figure 2 and 3, we have obtained the stable lifted methane jet flames diluted with helium for $(S c<1)$. So this study mainly focused on the nonpremixed lifted methane jet flames diluted with helium having $(S c<1)$. Now, how such lifted flames were stabilized has to be addressed. To explain the stabilization mechanism of such lifted flames spectrum analysis and radius of curvature measurement was done at the edge flame base and it will be discussed later.

\subsection{Stabilization mode}

Laminar lifted nitrogen diluted propane jet flames had two kinds of stabilization mode according to the position of flame base: developing and developed modes. The height of developing region for a free jet was well described by Won et. al. [8] as

$H_{\text {free }} / d=0.0165 \times R e_{\mathrm{d}}$

Here, $R e_{\mathrm{d}}$ was the Reynolds number defined as, $U_{\mathrm{O}} D / v$ and $v$ was the kinematic viscosity. Similar concept is used in the present study. The location of $H_{\text {free }}$ was marked in Figure 2(b) and Figure 3(b) as dotted lines. Lifted flames with $D=9.4$ $\mathrm{mm}$ and $0.95 \mathrm{~mm}$ are located in the developed region. The influence of buoyancy can be evaluated by the Richardson number as follows,

$R i=\Delta \rho \mathrm{g} D / \rho U_{\mathrm{O}}^{2}$

which is the ratio of the buoyancy-induced momentum to the jet momentum, where $\mathrm{g}$ is the gravitational acceleration, $\rho$ is the unburned density, and $\Delta \rho$ is the density difference between unburned and burned gases. The Richardson number was evaluated and depicted in Figure 2(b) and Figure 3(b). For $D=9.4 \mathrm{~mm}$ it was in the range of $0.88<R i<88.48$, which means buoyancy could have significant effect on stabilization mechanism. This could be the reason that, stationary lifted flames were observed for methane diluted with helium having $[0.7<S c<0.78]$ using $D=9.4 \mathrm{~mm}$, even though it was predicted that jet of pure fuel of $0.5<S c<1.0$ could not make the laminar lifted flame [1]. Such an important role of buoyancy effect on lifted flame stabilization in case of $U_{\mathrm{O}}<S_{\mathrm{L}}^{\mathrm{O}}$ in nitrogen-diluted propane jet flames has been already identified in detail [8]. However, the range of Richardson number in the laminar lifted flame with $D=0.95$ $\mathrm{mm}$ was 0.00027 to 0.0018 as shown in Figure 3(b), which means that buoyancy effect is negligible compared with jet momentum.

To further substantiate such two distinct regimes, the functional dependency of normalized liftoff height on normalized fuel nozzle exit velocity was shown in Figure 4.

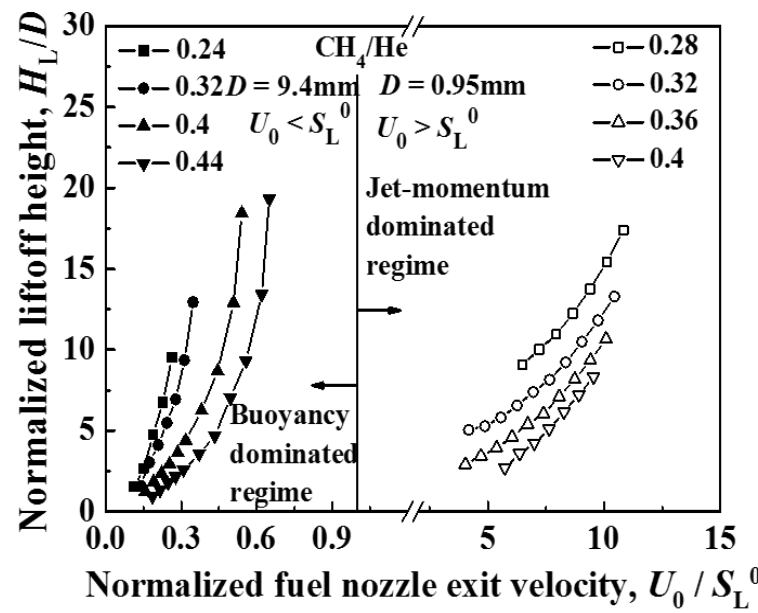

Figure 4. Normalized liftoff height with fuel nozzle exit velocity considering stoichiometric un-stretched nonadiabatic laminar burning velocity for two different fuel nozzles

Here, the stoichiometric un-stretched non-adiabatic laminar burning velocities, $S_{\mathrm{L}}{ }^{\mathrm{O}}$ were evaluated by using the oppdif code with detailed chemistry of GRI mechanism. Stationary lifted flames are obtained at $U_{\mathrm{O}}<S_{\mathrm{L}}{ }^{\mathrm{O}}$ for $D=9.4$ $\mathrm{mm}$; while, those exist even at $U_{\mathrm{O}}>S_{\mathrm{L}}{ }^{\mathrm{O}}$ for $D=0.95 \mathrm{~mm}$. 

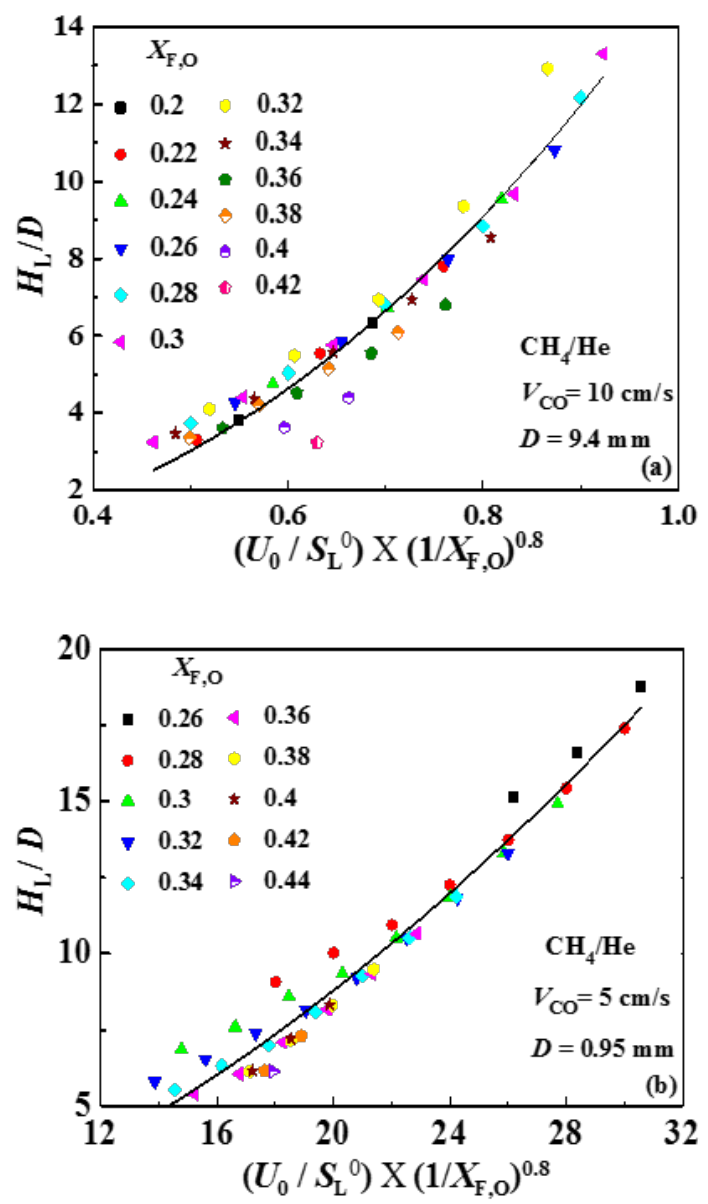

Figure 5. Characterizations of liftoff height behavior in far field region for (a) $D=9.4$ and (b) $0.95 \mathrm{~mm}$

The lifted flame with $D=0.95 \mathrm{~mm}$ had tri-brachial structure in developed region. It was reported that highly diluted propane jet lifted flame also had tri-brachial structure and its liftoff height was proportional to $\left(U_{\mathrm{O}} / S_{\mathrm{L}}{ }^{\mathrm{O}}\right)^{1.39}$ for small $X_{\mathrm{F}, \mathrm{O}}$ case in developed region and $\left(U_{\mathrm{O}} / S_{\mathrm{L}}{ }^{\mathrm{O}}\right)^{1.43}$ for high $X_{\mathrm{F}, \mathrm{O}}$ flame in developing region [8]. Similarly, Figure 5(a) and (b), shows empirical characterization of the liftoff height with related physical parameters for $D=9.4$ and $0.95 \mathrm{~mm}$ which corresponds to buoyancy and jet momentum dominated regimes respectively. The characterized liftoff height increased with an increase in the $U_{\mathrm{O}}$ and decrease in $X_{\mathrm{F}, \mathrm{O}}$. The best fits for liftoff heights $H_{\mathrm{L}}$, are obtained by the followings:

$H_{\mathrm{L}} / D=\left[\left(U_{\mathrm{O}} / S_{\mathrm{L}}{ }^{\mathrm{O}}\right)\left(1 / X_{\mathrm{F}, \mathrm{O}}\right)^{0.8}\right]^{2.34}, R=0.93$, for $D=9.4 \mathrm{~mm}$

$H_{\mathrm{L}} / D=\left[\left(U_{\mathrm{O}} / S_{\mathrm{L}}^{\mathrm{O}}\right)\left(1 / X_{\mathrm{F}, \mathrm{O}}\right)^{0.8}\right]^{1.69}, R=0.96$, for $D=0.95 \mathrm{~mm}$

where $R$ is the correlation coefficient for the curve fitting was $0.93,0.96$ respectively as shown above.

\subsection{Flame stability and regions of lifted flame}

Figure 6(a) and (b) shows the flame stability maps as a functions of $U_{\mathrm{O}}$ and $X_{\mathrm{F}, \mathrm{O}}$ for $V_{\mathrm{CO}}$ values of 10 and $5 \mathrm{~cm} / \mathrm{s}$, at ambient environment with $D=9.4$ and $0.95 \mathrm{~mm}$. In Figure 6(a), stationary lifted flames were appeared for $(\mathrm{CH} 4 / \mathrm{He})$ at $X_{\mathrm{F}, \mathrm{O}}=0.16$ to 0.6 using $9.4 \mathrm{~mm}$ nozzle. Flame flickering was observed for high $X_{\mathrm{F}, \mathrm{O}}>0.34$ and $U_{\mathrm{O}}>7 \mathrm{~cm} / \mathrm{s}$. Also, in Figure $6(\mathrm{~b})$, there were two lifted flame regimes observed using $0.95 \mathrm{~mm}$ nozzle. In regime-I lifted flames were observed at initial condition when flame was ignited and it keep lifted until blown out for $0.26<X_{\mathrm{F}, \mathrm{O}}<0.4$. But for 0.41 $<X_{\mathrm{F}, \mathrm{O}}<0.6$, after ignition flames were lifted and then due to change in flame shape $H_{\mathrm{L}}$ was decreased and thereby lifted flame were attached to the nozzle. Then with keep increasing the $U_{\mathrm{O}}$ flames were again lifted in regime-II. This behavior of lifted flame is demonstrated in Figure 7 , for $X_{\mathrm{F}, \mathrm{O}}=0.45$ with increasing $U_{\mathrm{O}}$. At $U_{\mathrm{O}}=70 \mathrm{~cm} / \mathrm{s}$, flame was first ignited and it was lifted flame. Furthermore, with keep increasing the $U_{\mathrm{O}}$ attached flame was observed and finally flame was again lifted at $U_{\mathrm{O}}=240 \mathrm{~cm} / \mathrm{s}$. In such lifted flames, at high $X_{\mathrm{F}, \mathrm{O}}>$ 0.63 and $U_{\mathrm{O}}>1150$ flame tip flickering was observed. Note that, the present study is mainly focused on the lifted flames with increasing $H_{\mathrm{L}}$ behavior with $U_{\mathrm{O}}$ in regime-II only.
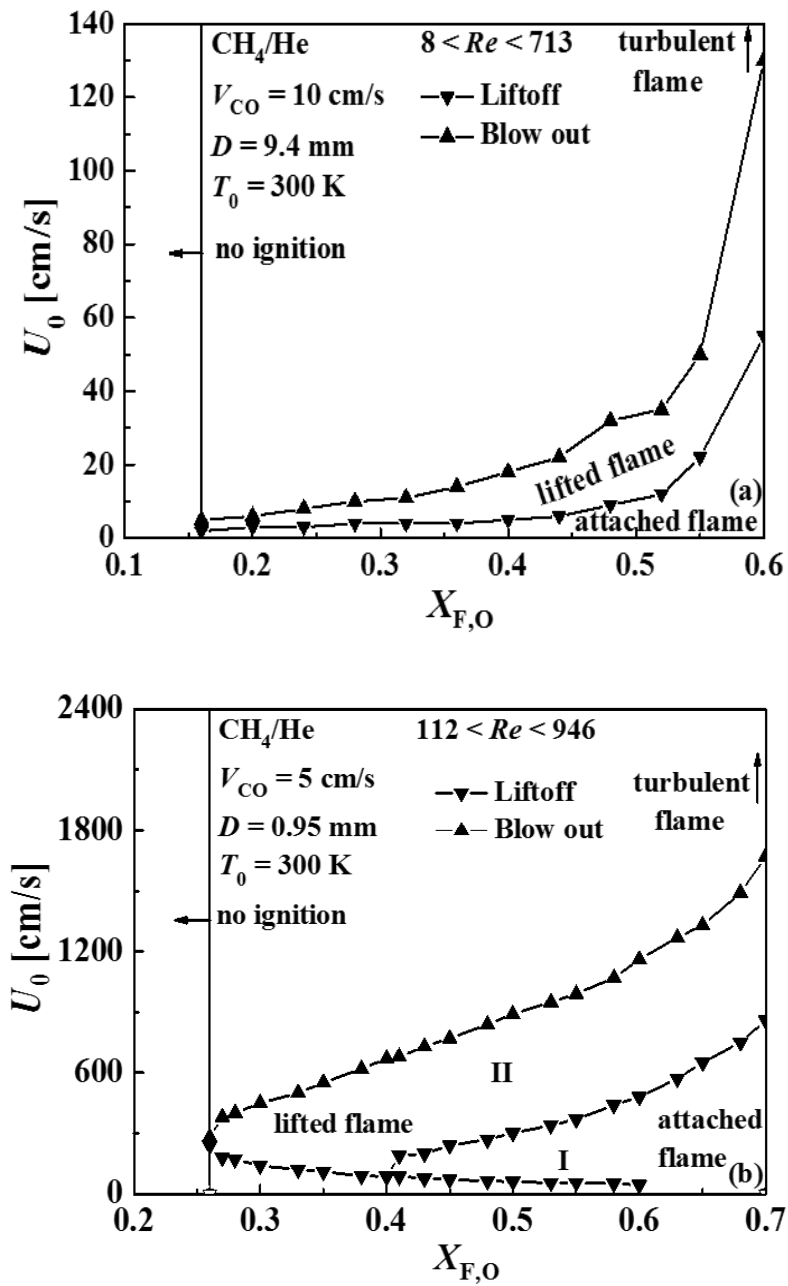

Figure 6. Flame stability map as a function of $U_{\mathrm{O}}$ and $X_{\mathrm{F}, \mathrm{O}}$ for (a) $D=9.4$ and (b) $0.95 \mathrm{~mm}$

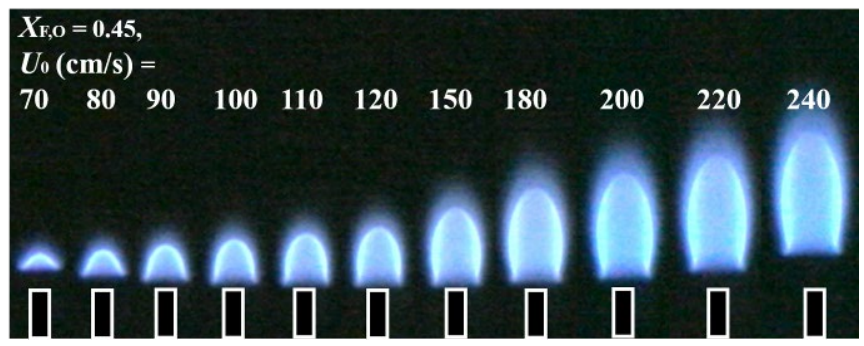

Figure 7. Behavior of lifted flames from ignition with increasing $U_{\mathrm{O}}$ for $D=0.95 \mathrm{~mm}$ 


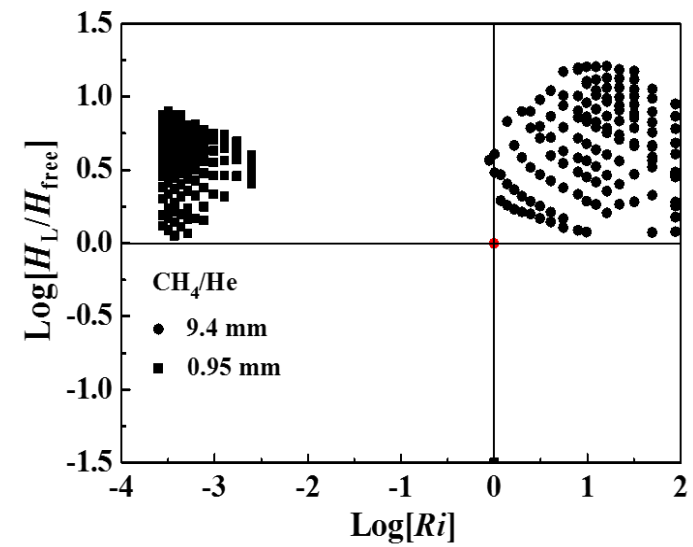

Figure 8. Regions of the laminar methane/helium lifted flames

Lift-off height divided by the length of developing region is a measure to tell where the lifted flame is in the developing zone or developed zone. If it is much larger than unity, then it is in the far field region hence jet theory could be applicable. If Richardson number is near unity, jet momentum and buoyancy force affects velocity distribution hence simple jet theory is not appropriate. Figure 8, shows our lifted flame data as function of $R i$ and $H_{\mathrm{L}} / H_{\text {free. }}$ Lifted flames with $D=$ $9.4 \mathrm{~mm}$ are affected by buoyancy force regardless of adegree of diluents though some of them are in far fields.

Moreover, lifted flames with $D=0.95 \mathrm{~mm}$ are in the far field and not affected by buoyancy force. So how the lifted flames (with $D=0.95 \mathrm{~mm}$ ) in the jet momentum dominated region were affected has to be addressed. Note that the stabilization mechanism is still the balance of edge flame speed to the local flow one [1-3]. This implies that edge flame speed has to increase even with mole fractions of helium despite reduction of mixture strength. To confirm it, spectrum analysis was done at edge flame base using monochromatic system and chemiluminescence intensities of $\mathrm{OH}^{*}$ (an indicator of heat release rate) [12-17] and other radicals are measured at various flame conditions. In addition, radius of curvature is also measured at edge flame base of triple flame.

\section{4 $\mathrm{OH}^{*}$ Chemiluminescence intensity at lifted flame base}

$\mathrm{OH}^{*}$ chemiluminescence intensity from lifted flame base of methane/helium fuel for $D=0.95 \mathrm{~mm}$ was obtained to know connections between blowout and heat release rate, in that it could be a measure of heat release rate [14]. Light from flame base image that made on the $600 \mu \mathrm{m}$ diameter optical fiber was scanned using monochromator and photomultiplier tube. The representative $\mathrm{OH}^{*}$ signal was demonstrated in Figure 9(a). It appears between 302 and 325 $\mathrm{nm}$ in our system since the slits on the monochromator are widely opened due to weak signal of the flame. Though there are non-zero baseline signals, the $\mathrm{OH}^{*}, \mathrm{CH}_{2} \mathrm{O}^{*}$, and $\mathrm{CH}^{*}$ peaks were clearly separable. Figure 9(a), shows the area under the peak of $\mathrm{OH}^{*}$ chemiluminescent intensity, between 3020 and 3250 Angstrom, after subtracting baseline intensity when triple point images were made on the fiber. With decreasing $X_{\mathrm{F}, \mathrm{O}}$ at constant velocity, $\mathrm{OH}^{*}$ chemiluminescence intensity increases at room temperature ambience. It was inversely proportional to $X_{\mathrm{F}, \mathrm{O}}$. Equations in the Figure 9(b), represents curve fitted results. Blowout occurs at $X_{\mathrm{F}, \mathrm{O}}=0.29$ when $U_{\mathrm{O}}=290 \mathrm{~cm} / \mathrm{s}$ and for $U_{\mathrm{O}}=360 \mathrm{~cm} / \mathrm{s}, X_{\mathrm{F}, \mathrm{O}}$ is 0.32 . So the asymptotic lines of the graphs are in good agreement with the $X_{\mathrm{F}, \mathrm{O}}$ at blowout. Since $\mathrm{OH}^{*}$ is related with heat release rate, flame releases more heat as decreasing $X_{\mathrm{F}, \mathrm{O}}$, this being a maximum at blowout. From this, it can be inferred that reactant fluxes increase to the edge flame, increasing the reaction rate, and hence edge flame speed increase. Based on the stabilization mechanism [1-3], this edge flame speed may balance with the local flow velocity and lifted flames were stabilized in developed region as discussed in previous sections. The importance of chemical species such as $\mathrm{OH}^{*}$, $\mathrm{CH}_{2} \mathrm{O}^{*}$ which are good indicators of heat release rate have been studied in the previous work [12-17].
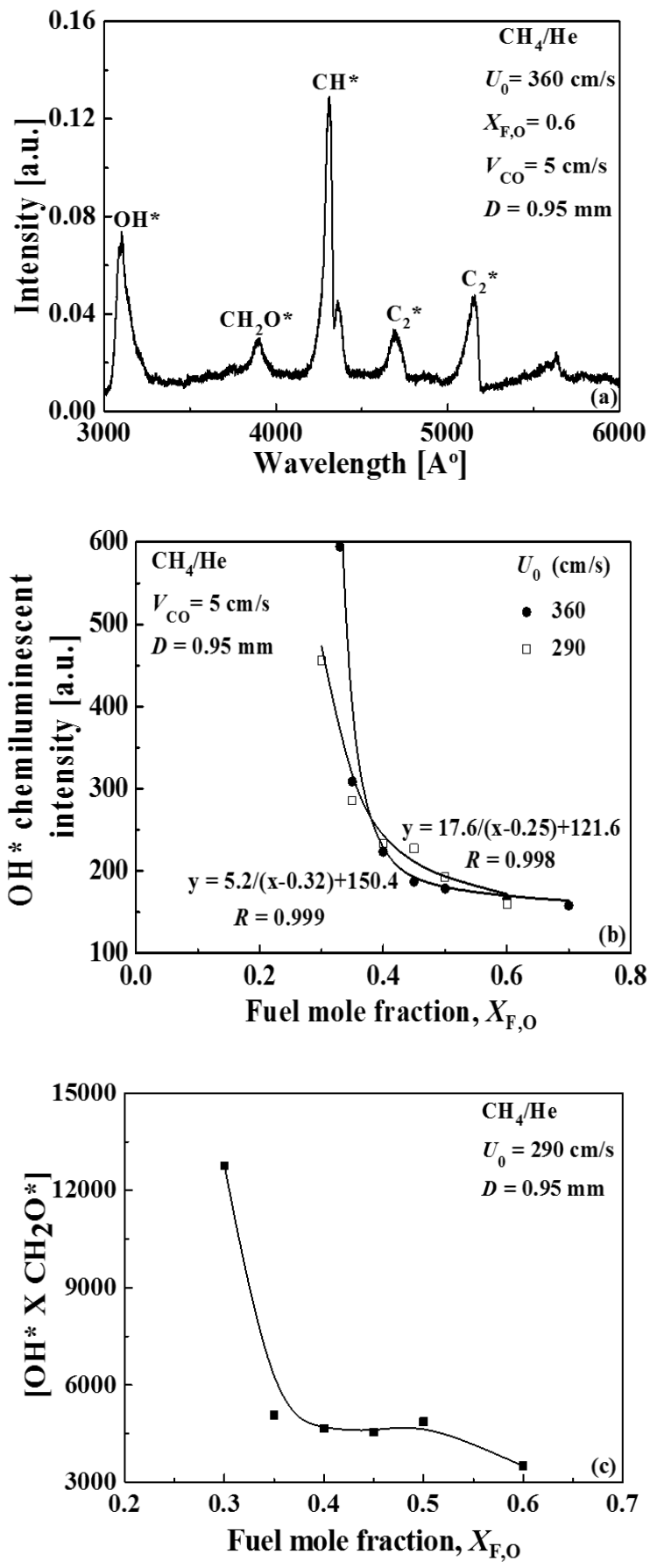

Figure 9. (a) Spectral wavelength scan of the lifted flame (b) Effect of fuel mole fraction on $\mathrm{OH}^{*}$ chemiluminescent intensity (c) Product of $[\mathrm{OH}] \mathrm{X}\left[\mathrm{CH}_{2} \mathrm{O}\right]$ as a marker for heat release rate 
In addition, it was shown that the product of $\mathrm{OH}^{*}$ and $\mathrm{CH}_{2} \mathrm{O}^{*}$ can be used as an excellent proxy for heat release rate in laminar flame [14]. In this manner, product of [OH] X $\left[\mathrm{CH}_{2} \mathrm{O}\right]$ is determined with $X_{\mathrm{F}, \mathrm{O}}$ as shown in Figure 9(c). It has the decreasing behavior with increasing $X_{\mathrm{F}, \mathrm{O}}$, which focus towards the influence of heat release rate affecting the edge flame speed as discussed before.

\subsection{Radius of curvature effect on the lifted flame base}

Edge flame speed is generally dependent upon the mixture strength, buoyancy, fuel concentration gradient (strain rate and thereby radius of curvature), and Lewis number [1-3]. Now we can discuss, what the main contribution of such a laminar lifted flame stabilization is in methane jet flame diluted with helium, in addition to the effect of heat release rate as mentioned in the last section. Because diluent addition decreases mixture strength, it has a negative effect on flame stabilization. Lewis number for helium addition was in the range of 1.08-1.36. For helium addition, it has a negative effect on edge flame speed such that the Lewis number increases with helium mole fraction. This implies that, the effect of Lewis number cannot be a main reason of flame stabilization. Thus important role on edge flame speed enhancement may be addressed to radius of curvature [3]. So radius of curvatures was measured at ambient temperature as shown in the Figure 10.

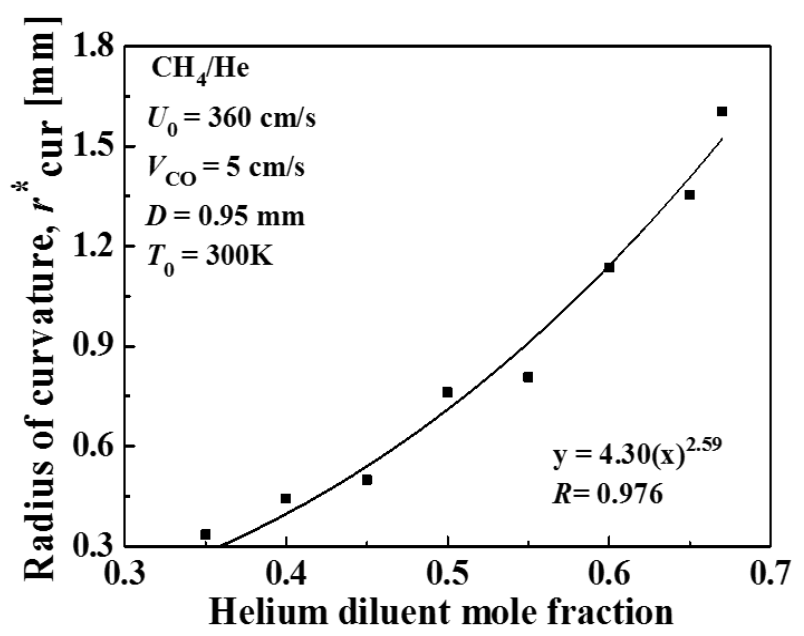

Figure 10. Radius of curvature $r^{*}$ cur of lifted methane jet flame with the addition of helium dilution

It shows the appreciable increase in radius of curvature with $\mathrm{He}$ mole fraction in jet-momentum dominated regime (with $D=0.95 \mathrm{~mm}$ ), thereby increasing edge flame speed. Consequently, for lifted methane jet flames diluted with helium, radius of curvature was increased with the addition of helium diluent which causes the increase in edge flame speed which could be balanced with the local flow one. Hence radius of curvature could also be the reason for flame stabilization. In such manner, flame stabilization mechanism in methane/helium lifted flames has been explained.

\section{CONCLUSION}

Laminar lifted methane jet flames diluted with helium were obtained experimentally for $0.5<S c<1$ using nozzles of diameters $9.4 \mathrm{~mm}$ and $0.95 \mathrm{~mm}$. Liftoff heights increase with nozzle exit velocity and inversely proportional to initial fuel mole fraction. Depending on the diluent and the size of nozzle, lifted flame was divided into two groups for methane/ helium fuel with $D=9.4 \mathrm{~mm}$, it was buoyancy driven in developed region and with $D=0.95 \mathrm{~mm}$, it was momentum driven in developed region. Lifted flames existed at $U_{\mathrm{O}}<S_{\mathrm{L}}{ }^{\mathrm{O}}$ for $D=9.4 \mathrm{~mm}$ and at $U_{\mathrm{O}}>S_{\mathrm{L}}^{\mathrm{O}}$ for $D=0.95 \mathrm{~mm}$. $\mathrm{OH}^{*}$ chemiluminescence intensity from light near the triple point for $\mathrm{CH} 4 /$ helium flame base, with $D=0.95 \mathrm{~mm}$ was inversely proportional to $X_{\mathrm{F}, \mathrm{O}}$ and had asymptotic line close to $X_{\mathrm{F}, \mathrm{O}}$ approximately equal to blowout mole fraction. Results shows that, increase in $\mathrm{OH}^{*}$ concentration and thereby heat release rate in addition to the increased radius of curvature contributed to the flame stabilization.

\section{UNCERTAINTY}

There are few measurement uncertainties that exists in the current study are: nozzle diameter, velocity calibration technique, camera resolution, monochromatic spectrum analysis, liftoff height measurement. The following table shows the uncertainty measurements for all applications used in the current study.

\begin{tabular}{|c|c|}
\hline Variable & Uncertainty \\
\hline Nozzle Diameter & $+/-5$ micron \\
\hline Camera Resolution & $+/-149$ micron \\
\hline $\begin{array}{c}\text { Velocity Calibration } \\
\text { Technique }\end{array}$ & $+/-5$ micron \\
\hline Spectrum Analysis & $+/-1$ micron \\
\hline Liftoff Height & $+/-5$ micron \\
\hline
\end{tabular}

\section{ACKNOWLEDGMENT}

This research was supported by Basic Science Research Program through the National Research Foundation of Korea (NRF) funded by the Ministry of Education, Science and Technology.

\section{REFERENCES}

[1] Chung SH, Lee BJ. (1991). On the characteristics of laminar lifted flames in a non-premixed jet. Combustion and Flame 86: 62-72. https://doi.org/10.1016/00102180(91)90056-H

[2] Lee BJ, Chung SH. (1997). Stabilization of lifted tribrachial flames in a laminar non-premixed jet. Combustion and Flame 109: 163-172. https://doi.org/10.1016/s0010-2180(96)00145-9

[3] Ko YS, Chung SH. (1999). Propagation of unsteady tribrachial flames in laminar non-premixed jets. Combustion and Flame 118: 151-163. https://doi.org/10.1016/S0010-2180(98)00154-0

[4] Ko YS, Chung SH, Kim GS, Kim SW. (2000). Stoichiometry at the leading edge of a tri-brachial flame in laminar jets from Raman scattering technique. Combustion and Flame 123: 430-433. https://doi.org/10.1016/s0010-2180(00)00169-3

[5] Lee J, Won SH, Jin SH, Chung S., Fujita O, Ito K. (2003). Propagation speed of tribrachial (triple) flame of propane in laminar jets under normal and micro gravity 
conditions. Combustion and Flame 134: 411-420. https://doi.org/10.1016/s0010-2180(03)00115-9

[6] Ruetsch GR, Vervisch L, Lina'n A. (1995). Effects of heat release on triple flames Physics of Fluids 7: 14471454. https://doi.org/10.1063/1.868531

[7] Chen JY, Echekki T. (2001). Numerical study of buoyancy effects on the structure and propagation of triple flames, Combustion Theory and Modelling 5: 499-515. https://doi.org/10.1088/1364-7830/5/4/301

[8] Won SH, Chung SH, Cha MS, Lee BJ. (2000). Lifted flame stabilization in developing and developed regions of co-flow jets for highly diluted propane. Proceeding of the Combustion Institute 28: 2093-2099. https://doi.org/10.1016/s0082-0784(00)80618-9

[9] Smooke MD, Ern A, Tanoff MA, Valdati BA, Mohammed RK, Marran DF, Long MB. (1996). Computational and experimental study of no in an axisymmetric laminar diffusion flame. Symposium International on Combustion 26: 2161-2170. https://doi.org/10.1016/s0082-0784(96)80042-7

[10] Qin X, Puri IK, Aggarwal SK. (2002). Characteristics of lifted triple flames stabilized in the near field of a partially premixed axisymmetric jet. Proceeding of the Combustion Institute 29: 1565-1572. https://doi.org/10.1016/s1540-7489(02)80192-4

[11] Plessing T, Terhoeven P, Peters N, Mansour MS. (1998). An experimental and numerical study of a laminar triple flame. Combustion and Flame 115: 335-353. https://doi.org/10.1016/s0010-2180(98)00013-3

[12] Medwell PR, Blunck DL, Dally BB. (2014). The role of precursors on the stabilization of jet flames issuing into a hot environment. Combustion and Flame 161: 465474. https://doi.org/10.1016/j.combustflame.2013.08.028

[13] Gordon RL, Masri AR, Mastorakos E. (2008). Simultaneous Rayleigh temperature, $\mathrm{OH}$-and $\mathrm{CH}_{2} \mathrm{O}$-LIF imaging of methane jets in a vitiated coflow. Combustion and Flame 155: 181-195. https://doi.org/10.1016/j.combustflame.2008.07.001

[14] Gordon RL, Masri AR, Mastorakos E. (2009). Heat release rate as represented by $[\mathrm{OH}] \mathrm{X}\left[\mathrm{CH}_{2} \mathrm{O}\right]$ and its role in auto-ignition. Combustion Theory and Modelling 13: 645-670.

[15] Fayoux A, Zahringer K, Gicquel O, Rolon JC. (2005). Experimental and numerical determination of heat release in counterflow premixed laminar flames. Proceeding of the Combustion Institute 30: 251-257. https://doi.org/10.1016/j.proci.2004.08.210

[16] Dworkin SB, Schaffer AM, Connelly BC, Long MB, Smooke MD, Puccio MA, McAndrew B, Miller JH. (2009). Measurements and calculations of formaldehyde concentration in a methane/N2/air, non-premixed flame:
Implication for heat release rate. Proceeding of the Combustion Institute 32: 1311-1318. https://doi.org/10.1016/j.proci.2008.05.083

[17] Dawson JR, Worth NA. (2014). Flame dynamics and unsteady heat release rate of self-excited azimuthal modes inanannular combustor. Combustion and Flame 161 : 2565-2578. https://doi.org/10.1016/j.combustflame.2014.03.021

[18] Chung SH. (2007). Stabilization, propagation and instability of tribrachial flames. Proceeding of the Combustion Institute 31: 877-892. https://doi.org/10.1016/j.proci.2006.08.117

[19] Larbi AA, Bounif A, Bouzit M. (2018). Comparisons of LPDF and MEPDF for lifted $\mathrm{H} 2 / \mathrm{N} 2$ jet flame in a vitiated coflow. International Journal of Heat and Technology 36(1): 133-140. https://doi.org/https://doi.org/10.18280/ijht.360118

[20] Abderrahmane H, Brahim N, Abdelfatah B, Nouereddine A.M. (2017). Laminar natural convection of power-law fluid in a differentially heated inclined square cavity. Annales de Chimie - Science des Materiaux 41(3-4): 261-281. https://acsm.revuesonline.com/article.jsp?articleId=399 45

[21] Buckmaster J, Peters N. (1988). The infinite candle and its stability-A paradigm for flickering diffusion flames. Symposium International on Combustion 21: 18291836. https://doi.org/10.1016/s0082-0784(88)80417-x

\section{NOMENCLATURE}

$\mathrm{D}$

UO

$\mathrm{g}$

VCO

SLO

$\mathrm{XF}, \mathrm{O}$

Hfree

HL

$\mathrm{Sc}$

$\operatorname{Re}$

$\mathrm{Ri}$

$\mathrm{R}$

r*cur

\section{Greek symbols}

V nozzle diameter, $\mathrm{mm}$

nozzle exit velocity, $\mathrm{cm} . \mathrm{s}^{-1}$

gravitational acceleration, $\mathrm{m} . \mathrm{s}^{-2}$

coflow velocity, $\mathrm{cm}$. $\mathrm{s}^{-1}$

stoichiometric un-stretched non-adiabatic laminar burning velocity, $\mathrm{cm} . \mathrm{s}^{-1}$

fuel mole fraction

length of developing region

liftoff height, $\mathrm{mm}$

Schmidt number

Reynolds number

Richardson number

correlation coefficient

radius of curvature, $\mathrm{mm}$
Kinematic viscosity, $\mathrm{m}^{2} . \mathrm{s}^{-1}$ 